\title{
BREVES APUNTES SOBRE LOS FUNDAMENTOS DEL DERECHO EUROPEO Y EL DERECHO ROMANO
}

\section{Luis Mariano Robles Velasco ${ }^{1}$}

\section{Resumen}

Ante la posibilidad de una nueva asignatura titulada "Fundamentos del Derecho Europeo", no está de más recordar el papel determinante que jugo el Derecho Romano en la formación del derecho europeo, su influencia en países como Inglaterra, Alemania, Francia, España, y otros muchos, incluidos otros ordenamientos exóticos como Japón o la India. Y así mismo, que fuera de ser considerado un mero derecho histórico, es por el contrario aún vigente, en la Europa actual como lo reiteran las más recientes novedades como el código de obligaciones europeo o en materia de sucesiones.

Palabras clave: Fundamentos del Derecho Europeo; Derecho Romano; Derecho Inglés; Derecho Francés; Derecho Foral; Derecho Comunitario; Sucesiones; Certificado Europeo de Sucesiones.

\section{INTRODUCCIÓN}

Recientemente tuve ocasión de acudir a un Seminario de Derecho Romano en la Universidad Católica de Murcia (UCAM), donde aparte de las consabidas intervenciones académicas sobre diversos temas romanísticos de hondura científica, surgió en el curso de la exposición del profesor Torrent ${ }^{2}$ la alusión a la nueva asignatura de "Fundamentos del Derecho Europeo". Asignatura que al parecer, colegas romanistas de Italia y algunas voces de nuestro país han recogido como una especie de refundición de distintas áreas de conocimiento que antes estaban imbricadas en Historia del derecho, Derecho Eclesiástico y Derecho Romano.

Parece como si en los últimos tiempos hubiera ido en franca retirada nuestra asignatura de Derecho Romano pretendiendo su minusvaloración, reducción o cuando no, más o menos abiertamente su desaparición. Y eso no.

Del papel de nuestra disciplina se ha hablado mucho y en diversos foros. Y sin duda, voces más autorizadas. El tema ya viene de lejos.

\footnotetext{
${ }^{1}$ Profesor contratado doctor, vinculado a la Universidad de Granada, donde ingresó como Profesor Asociado en el Departamento de Derecho Mercantil y Derecho Romano, área de Derecho Romano, Facultad de Derecho. E-mail: lmrobles@ugr.es

${ }^{2}$ A. TORRENT, Intervención en el Seminario de Derecho Romano del 15/06/2016. Universidad Católica de San Antonio, Murcia.
} 
No está de más recordar el peligro, al hilo de la anterior ley de Reforma Universitaria de 1983 (Ley Orgánica 11/ 1983, de 25 de Agosto, BOE de 1 de Septiembre de 1983), que introdujo en la Universidad española, un nuevo modelo estructural y de docencia, cuyas consecuencias se han dejado sentir hasta nuestros días, a consecuencia de las conclusiones del entonces denominado Grupo de Trabajo 10.

El Grupo de Trabajo 10, terminó sus propuestas sobre el Derecho Romano (mayo de 1987) con un Derecho Romano que podía haber quedado en el proyecto del Plan como asignatura optativa, casi testimonial pero la reacción de la romanística española y del mundo jurídico nacional en su conjunto produjeron una magnifica y responsable meditación que venía a defender al Derecho Romano como disciplina imprescindible en la formación de los futuros juristas españoles. Esto trajo consigo una magnifica serie de trabajos que una vez aprobadas las entonces Directrices de 1990 vinieron a convertirse en el hilo conductor de un gran debate en torno a los objetivos de la propia formación jurídica y del lugar que en ésta debería de ocupar la historia y las instituciones del Derecho Romano bajo el título docente en aquel entonces de "El Derecho en Roma y su Recepción en Europa”’.

En este sentido, la fijación de los objetivos de los estudios de Derecho y de la formación de los futuros juristas españoles en consonancia con la tradición, siempre ha constituido un presupuesto previo para la realización de dichos estudios, como argumentaba López Rosa ${ }^{4}$, en perfecta sintonía con la máxima escolástica finis est primus in intentionem, ultimus in executionem.

Es frecuente, y desde luego no es novedoso, que quienes centran su actividad en torno a la investigación jurídica, se interroguen acerca de si continua siendo válido para los estudiantes de derecho el conocimiento de ciertas materias, como el Derecho Romano, alegando sin profundizar convenientemente en ello, que el Derecho Romano no alcanza a tener una expresa aplicación práctica.

Es algo que ha sido muy discutido, cuál es el papel de nuestra disciplina en el contexto actual de la formación jurídica. Y fundamentalmente, lo ha sido porque en las grandes codificaciones del siglo XIX, el Derecho

\footnotetext{
${ }^{3}$ Aparte del debate en el que intervinieron entre otros los profesores BALZARINI, CRUZ, WACKE en "Reunión de la Sociedad española de Derecho Romano el 26 de Septiembre de 1987”, es de citar Boletín Del Ilustre Colegio De Abogados De Madrid, Revista Jurídica General, nº 6, noviembre-Diciembre 1987 dedicado monográficamente a la defensa del Derecho Romano, donde en su editorial, el Prof. Martínez Val afirmaba que "la defensa del Derecho Romano es una trinchera en la lucha por el Derecho, que no se puede abandonar, ni perder..." En este mismo número colaboraron juristas como IGLESIAS SANTOS, GARCIA GARRIDO, FERNÁNDEZ DE BUJAN A., REINOSO F., y ROSET. Así mismo es de destacar la ayuda corporativa de los Colegios Notariales de España, el Colegio Nacional de Registradores de la Propiedad y Mercantiles de España, y la Real Academia de Jurisprudencia y Legislación. Entre otros estudios dignos de mención, se puede citar: GARCIA GARRIDO, y EUGENIO DIAZ, Estudios De Derecho y formación de juristas, Madrid 1988; BETANCOURT F., En defensa del Derecho Romano, CIDHPPN, 9-10, Enero 1988, Barcelona, pp. 2269 ss.; FERNÁNDEZ DE BUJAN F., La Reforma de los Estudios de Derecho, Madrid 1992; LOZANO CORBI, Roma y su gran aportación al mundo: el Derecho Romano, Zaragoza 1993; LOPEZ ROSA, Estudios de Derecho y Formación de juristas. Un apunte a propósito de la reforma de los planes de estudio, CIDHPPN, 15-16, Febrero 1993, Barcelona, pp. 3791 ss. ${ }^{4}$ I JORNADAS ANDALUZAS DE DERECHO ROMANO, JAÉN 1997. ISBN.- 84-89869-94-4, "Derecho Romano y formación jurídica al amparo de la legislación reformista española”, LOPEZ ROSA, R., pp. 15 ss. 
Romano que había venido siendo reelaborado por sucesivas generaciones de juristas, hasta ese momento había formado parte del derecho vigente en no pocos países, pero que a partir de la codificación ya no era así.

La Universidad, en palabras de Duplá Marín ${ }^{5}$, que ya era una institución central en la Edad Media ${ }^{6}$, nació en aquel entonces, con la misión de impartir una enseñanza superior, pero entre nosotros, el concepto de Universidad no es una idea absoluta que pueda construirse especulativamente, sino un concepto cargado de tradición y de historia, que solo apelando a la historia cabe definir, en palabras de Giner de los Ríos?

Es cierto que al aludir a la Universidad de hoy, no se pueden desconocer los antecedentes históricos, pero como matizan Michavila y $\mathrm{Calvo}^{8}$, la comparación de la Universidad de hoy con la de antaño es inconsistente ya que cada una de ellas ha tratado de responder a una realidad social distinta en la que se han asentado. Así, mientras en la Universidad Medieval se dedicaba esencialmente a la trasmisión de los saberes ya establecidos ${ }^{9}$, es sólo a partir del siglo XIX cuando empieza a adquirir relieve la investigación como actividad propia universitaria.

Al transformarse las circunstancias y devenir en un sistema jurídico del pasado, cuyo contenido debía de ser reconstruido históricamente, se produjo un evidente desánimo y falta de motivación por parte de todos, lo que ha conducido a lo largo de los últimos decenios a enconadas polémicas, en torno a la necesidad de su estudio y encuadramiento entre las disciplinas jurídicas, abocándose finalmente a la cuestión de la grave situación que en la actualidad se presenta en nuestra disciplina, en donde se corre el riesgo más o menos cierto de ser reducida a la categoría de saber jurídico de orden secundario, de cual se puede prescindir, o bien utilizando una expresión más académica más al uso, dejada como asignatura optativa o cuatrimestral, o cuando no integrada o enlazada con otras asignaturas hermanas ... pero divergentes.

Ello denota todos los visos de un saber o configuración sesgada, cuando no una falta de proyección y de continuidad histórica en la necesidad de una asignatura con tan clara proyección académica y europea, lo que representa una amenaza no solo dirigida al Derecho Romano, sino a Derecho en general.

Quienes tales cosas propugnan, parece que tuvieran la intención de postergar el estudio del Derecho Romano a una parcela tan minoritaria y minimizada que casi podría augurarse que adolecería de una visión miope y sesgada, a contracorriente de la visión europeísta e integradora de la ciencia jurídica que marcan los tiempos actuales.

Si tales amenazas se consolidaran, se llegarían en tales circunstancias a producir para la sociedad una clase de juristas, que pasarín con los ojos cerrados y sin el aporte de la sensibilidad necesaria que todo jurista

\footnotetext{
${ }^{5}$ DUPLÁ MARIN, La enseñanza del Derecho Romano, en "EL DERECHO ROMANO EN LA UNIVERSIDAD DEL SIGLO XXI, op. Cit., pp. 309 ss.

${ }^{6}$ Según LATORRE, "La Universidad Medieval es una de las más grandes creaciones de la civilización occidental, pero su grandeza nace de su perfecto enraizamiento en la sociedad que le dio vida”. LATORRE, Universidad y sociedad, Barcelona 1994, p. 11.

${ }^{7}$ GINER DE LOS RIOS, Sobre reformas en nuestras Universidades, Escritos sobre la Universidad, Madrid 1990, p. 108.

${ }^{8}$ MICHAVILA Y CALVO, La Universidad española hacia Europa, Madrid 2000, p. 21.

${ }^{9}$ CLARAMUNT, Universidad medieval y transmisión de saberes, Valladolid 1997, pp. 9 a 34.
} vol.10, n. 01, Rio de Janeiro, 2017.pp. 291-316 
necesita, ya que desconocer la existencia de los orígenes, o el conocimiento de los destinos de las normas jurídicas, cercenaría la posibilidad de introducirse en una atmósfera de cultura jurídica y de educación clásica, que con su origen en el mundo helénico, se desarrolla en Roma, y se difunde por toda Europa y por gran parte del mundo. Y es precisamente, en la formación de Europa de la que es parte esencial el Derecho Romano. Una autentica enseñanza universitaria, entendida como Universitas ${ }^{10}$ es lo que dio sentido a la Universidad como fuente del saber. Y esta enseñanza no puede, ni debe suprimir o reducir materias o disciplinas de tan aquilatado valor científico y formativo.

El Derecho Romano, bien por sí mismo, bien por la recepción del Derecho Común en la práctica totalidad de los países europeos es un Derecho aplicable, lo que representa el nervio carnal y espiritual de nuevas legislaciones, no solo como en el pasado con los Códigos Civiles de la codificación decimonónica, sino con la proyección necesaria para los países, no solo latinos, sino los nuevos europeos ${ }^{11}$. Y de ello es de lo vamos a tratar.

\section{RECEPCIÓN E INFLUENCIA HISTÓRICA DEL DERECHO ROMANO EN DISTINTOS PAÍSES EUROPEOS}

Aunque para los autores del Renacimiento e incluso los de la Ilustración, la caída del imperio Romano acaeció de una manera violenta, en donde las sucesivas oleadas bárbaras destruyeron la civilización antigua y las instituciones romanas con una visión catastrofista, mantenida entre otros por Pérez Pujol y Cárdenas, según señala Font Rius ${ }^{12}$, en realidad las llamadas invasiones de los bárbaros no fueron otra cosa que desplazamientos de pueblos enteros entre los años 378 y 493, que alteraron la vida del imperio en todas sus manifestaciones, cambiando la faz del mundo y marcando el tránsito de la Edad Antigua a la Edad moderna ${ }^{13}$.

Desde este punto de vista, el pueblo occidental del continente, desatendido y desprotegido, y que no profesaba ninguna simpatía a los bizantinos, se agrupa entorno a sus obispos, convertidos ahora en protectores de la cultura romana, recuperando su antigua voluntad de servicio y destinando a ello su estructura organizativa, riquezas y prestigio, según Cannata ${ }^{14}$.

\footnotetext{
${ }^{10}$ Mientras que el término Studium Generale era el que inicialmente designaba esta institución académica, como lugar donde los estudiantes eran recibidos y los asuntos estudiados, Universitas, se refería a un conjunto de personas, corporación legal dotada de personalidad jurídica. DUPLÁ MARÍN, La enseñanza del Derecho Romano..., op. Cit, p. 310.

${ }^{11}$ ROBLES VELASCO, L.M., EL FUTURO CODIGO EUROPEO DE CONTRATOS, ¿UNA NUEVA RECEPCION?, RIDROM (Revista Internacional de Derecho Romano). Octubre 2010. Disponible en: www.ridrom.uclm.es, no de Octubre 2010.

${ }^{12}$ FONT RIUS, Historia del Derecho Español, Barcelona 1969, p. 84 ss.

${ }^{13}$ PANERO GUTIERREZ, R, y otros "EL DERECHO ROMANO EN LA UNIVERSIDAD DEL SIGLO XXI", Cáp. 20 "El Derecho Romano y su recepción en Europa,"op. Cit,. pp.122 ss.

${ }^{14}$ CANNATA, Historia de la ciencia jurídica Europea, op. Cit, p. 106.
} 
Con ello, y ya al final del siglo VI, el papa Gregorio I (590-604) fija los fundamentos de la unidad religiosa de Occidente sobre la Iglesia de Roma y sentando las bases de lo que a partir del Siglo IX se denominó el Sacro Imperio Romano Germánico.

Por otra parte, el avance del Islam entre los siglos VII y IX, que va a apoderarse del Mediterráneo, Siria, Palestina, Egipto, Norte de África, Hispania, penetrando en las Galias hasta ser contenidos por el mayor domus regiae Carlos Martel en Poitiers (732), es lo que lleva a decir a Koschaker ${ }^{15}$ que en realidad, "no fueron los germanos los que acabaron con el Imperio Romano, sino el Islam”.

Así pues, fue la Iglesia, el Sacro Imperio Romano Germánico, y el Derecho Romano (un mismo Dios, un mismo papa, un mismo emperador y un mismo derecho), lo que a la postre vino a significar la cristalización de la idea del Imperio Cristiano en los distintos reinos de la naciente Europa, que tuvo su momento fundacional en la coronación de Carlomagno, el día de navidad del año 800, el cual se puede considerar la primera manifestación de la unidad política, que hoy llamamos Europa, como apuntaba $\operatorname{Koschaker}^{16}$. Precisamente es Koschaker ${ }^{17}$, como es sabido que en la mayoría de sus trabajos coloca al Derecho romano como eje unificador europeo ${ }^{18}$.

Llegaba a esta conclusión, ya que a decir de Koschaker, esta superioridad científica y cultural que representa el Derecho Romano se pone particularmente de manifiesto en la recepción del sistema romanístico en culturas y sistemas tan distintos del europeo como el japonés ${ }^{19}$. Según sus propias palabras, Koschaker $^{20}$ decía que "... Cuando Japón se europeíza a pesar de mantener relaciones culturales muy intensas con EEUU, no recibe el Derecho Anglo-americano, sino el Code Civil Français y los proyectos de Código Civil Alemán...".

\section{La Influencia Del Derecho Romano En Inglaterra}

\footnotetext{
${ }^{15}$ KOSCHAKER, Europa y el Derecho romano, (trad. SANTA CRUZ TEIJERO) Madrid, 1955, p.37-39.

${ }^{16}$ Añade Koschaker, que el cenit en la evolución de Europa lo alcanza el siglo XIX al incorporarse los países balcánicos a la cultura europea, y penetrar éste profundamente en Rusia, y que por otra parte, a través del imperio colonial hispano, portugués, holandés y francés, lo fue a su vez en otras tierras. KOSCHAKER, Europa y el Derecho romano, op. Cit., pp. 21 ss.

${ }^{17}$ KOSCHAKER, Europa y el Derecho romano, op. Cit., pp. 478: "Hay un derecho natural relativo y europeo que se obtiene no por la vía especulativa, sino por vía de la razón con un estricto rigor histórico, mediante el parangón y comparación de los sistemas de Derecho Privado que más han contribuido a la construcción jurídica de Europa y del mundo, y en cuya cúspide figura el Derecho Romano, como elemento unificador de estos sistemas. Un derecho que condensa las experiencias jurídicas de los pueblos que con su cultura han cooperado a la formación de Europa... Aun hoy, existen medios de convertir el Derecho Romano en el cumplimiento de su función histórica, que es la de actuar como intermediario de los grandes sistemas europeos de Derecho Privado extendidos por todo el orbe".

${ }^{18}$ LOZANO CORBI, Roma y su gran aportación al mundo: El Derecho Romano, Zaragoza, 1993, p.39 y 40.

${ }^{19}$ Interesante el artículo de HAYASHI, TOMOYOSHI, El Derecho Romano y el Código Civil en el Japón Moderno: sistemática, propiedad y copropiedad, Revista Chilena de Derecho 2009, 36, pp. $9-21$.

Disponible en: http://www.redalyc.org/articulo.oa?id=177014521002, ISSN 0716-0747.

${ }^{20}$ KOSCHAKER, Europa y el Derecho romano..., op. Cit., pp. 22 ss.
} 
Para $\operatorname{Koschaker}^{21}$, la recepción no tuvo el mismo éxito en Inglaterra que en otros países de Europa precisamente debido al hecho de existir un temprano desarrollo de la clase de los juristas. En la recepción, se trataba de sustituir un derecho jurisprudencial por otro judicial, adaptado a las circunstancias y privilegios locales... Y puestos a escoger, entre un derecho romano -derecho de glosadores y comentarista- y un derecho inglés derecho de los juristas de la corte-, escogieron el suyo ${ }^{22}$. El enfrentamiento de la nobleza con el rey, en realidad, favorecía a los juristas, al igual que en el orden político favorecía al monarca, un sistema de derecho judicial donde los jueces son nombrados por la Corona. Por ello, el Derecho Romano Justinianeo, evidentemente jurisprudencial, no se utiliza simplemente porque no favorece la causa de los reyes ingleses (lo que fue considerado como Cesarismo).

En su formación histórica, el Derecho Inglés presenta caracteres propios y específicos que le diferencian de los derechos continentales de tradición romanística, según García Garrido ${ }^{23}$, en donde se contrapone un derecho legal o legislado, el Statute Law, y un derecho jurisprudencial, o Common Law ${ }^{24}$.

Por tanto y en el caso concreto del Derecho anglosajón, frente a una jurisprudencia académica enrevesada de tecnicismos legales basada en textos romanos codificados, aparece una jurisprudencia judicial basada en una labor casuística, interpretativa y orientadora, de los jueces ingleses, como por otra parte ocurría en dicha época con otras coronas, como la antigua Jurisprudencia del Parlamento de París, la de las Reales Audiencias de España y de la América Española, jurisprudencia más presta a dar una solución al caso en litigio, que a responder con una perfecta adecuación a los textos o al literal sentido de la ley.

Por ello, para tratar de comprender el derecho inglés, y por ende el derecho americano de buena parte de los Estados del Norte, hay que conectar por tanto con la evolución del Common Law anglosajón y engarzarlo con las luchas entre la corona y la nobleza ${ }^{25}$ británica, es decir entre un derecho feudal y un derecho romanizado, ya que no cabe desconocer por otra parte, que algunos monarcas ingleses prohibieron el Derecho Romano ${ }^{26}$ por

\footnotetext{
${ }^{21}$ KOSCHAKER, Europa y el Derecho romano..., op. Cit., p. 316.

${ }^{22}$ KOSCHAKER, Europa y el Derecho..., op. Cit., p.308: "La resistencia inglesa frente al Derecho Romano se debe exclusivamente al estamento de juristas. Aceptarlo en la forma en que le dieron glosadores y comentaristas hubiera significado para los ingleses permutar su derecho de juristas por otro también de juristas".

${ }^{23}$ GARCÍA GARRIDO, MJ., Derecho Privado Romano, Casos, Acciones e Instituciones, Madrid 2003, pp. 56 ss.

${ }^{24}$ Sobre la formación histórica del Derecho Inglés, se puede citar la siguiente bibliografía: PLUCKNETT, $A$ Concise history of the Common Law, London 1956; MILSON, Historycal foundations of the Common Law, London 1969; PATON, A texbook of Jurisprudence, Oxford 1972; CRISCUOLI, Introduzione allo studio del diritto inglese, le fonti, Milano 1981; PUIG BRUTAU, La jurisprudencia como fuente del Derecho, Barcelona S.f. CANNATA-GAMBARO, Lineamenti di storia della giurisprudenza europea, I y II, Torino 1984.

${ }^{25}$ H. POTTER, Historical introduction to English Law, London 1958.

${ }^{26} \mathrm{La}$ enseñanza del Derecho Romano fue prohibida por Esteban II, en el 1151 en Inglaterra. Y esta prohibición fue más temprana y reiterada que el resto de Europa. Lo que prueba que existía pues, otro derecho que había que defender contra el romano, el cual debería de estar plenamente desarrollado -o al menos no tan fragmentario- KOSCHAKER, Europa y el Derecho romano, op. Cit., pp. 22 ss.
}

${ }^{26}$ CAMACHO EVANGELISTA, F., Historia del Derecho Romano y su recepción en Europa, Granada 1994, p. 397 ss. vol.10, nº. 01, Rio de Janeiro, 2017.pp. 291-316 
tratar de mantener las prerrogativas de la corona inglesa, teniendo que acceder en distintas actas al reconocimiento de los derechos individuales.

Como ejemplo de algunas de estas las luchas entre la corona y la nobleza, baste recordar que Carlos I de Inglaterra, sucesor de Jacobo I en 1625 se enfrentó a la rebelión escocesa en 1640, disolvió el Parlamento en varias ocasiones, y encarcelado desde 1647 a 1649, fue finalmente ajusticiado por orden de un tribunal dependiente del Parlamento -y por la intervención de Oliverio Cromwell- el 30 de enero de $1649^{27}$. La restauración monárquica se llevará a cabo con Carlos II $(1660)^{28}$.

Al final la conquista de la libertad conduce en las colonias al Acta de Tolerancia de Maryland (1649), y al propio reconocimiento de las colonias americanas por Carlos II (Rhode Island). La libertad de los derechos se concreta en la Petition of Rights (1628) con la libre práctica de la religión $(1663)^{29}$, con la llegada del May Flower y la celebración del día de los peregrinos o día de acción de gracias; el reconocimiento de Habeas Corpus -ningún ciudadano puede ser detenido sin orden judicial expresa, y ha de ser puesto en libertad en plazo de 3 días- en 1679, el Bill of Right $(1689)^{30}$ carta de los ciudadanos ingleses: Los ingleses pueden consultar al parlamento asuntos de Estado.

En realidad, en Inglaterra ${ }^{31}$, el llamado derecho inglés sea particular o regio descansa sobre la base del Ius Commune (o Common Law), en cuyo conocimiento se habían formado los juristas ingleses, funcionando al modo de un documentado derecho científico o racional ${ }^{32}$. En la práctica, el derecho inglés es un derecho que

\footnotetext{
${ }^{27} \mathrm{La}$ contienda arranca en 1628 con la reclamación ante la Cámara de los Comunes a instancias de John Eliot, John Pym y Thomas Wemwolth, de una serie de mejoras en cuestiones fiscales, estamentales, y de diversos ordenes, con la respuesta de la disolución del Parlamento en 1629, con lo que se inicia un periodo absolutista donde el rey toma las riendas de la vida pública, rechaza el calvinismo, reforma la liturgia anglicana siguiendo las pautas de la religión católica frente a la ideología calvinista, con un predominio de las congregaciones puritanas.

Introdujo nuevos impuestos, en base a la idea de Rex est Lex, justificando el origen divino del poder monárquico, condenando a todos aquellos que propugnaran la idean de un poder independiente o popular como sinónimo del poder papal, que representaba una amenaza contra el puritanismo.

El máximo representante de la oposición John Pym, pide una monarquía parlamentaria, declarando ilegales los actos de gobierno del rey Carlos I, el rey huye, refugiándose primero en Oxford en 1643 y después en Escocia, iniciándose un periodo bélico que durará hasta 1649.

En este periodo destaca la figura de Oliverio Cromwell y la creación del ejercito de los santos (Ironside). Cromwell es un puritano convencido de llevar a cabo una misión religiosa en contacto con la divinidad. Por ello, lleva a cabo una serie de acciones bélicas que a la postre le convierte en dueño de la situación política.

El rey CARLOS I, es entregado a cambio de 40.000 libras. Cromwell entra en Edimburgo en 1648 propiciando un golpe de Estado 26 de septiembre de 1648. El rey es condenado a muerte y ajusticiado el 30 de enero de 1649. CREMADES LIÑNAN, La Europa que surge de la paz de Westfalia, (Gran Historia UniversalXVI),Madrid 1984, pp. 118 ss.

${ }^{28}$ CREMADES LIÑAN, La Europa que surge de la paz de Westfalia, op. Cit., p 119.

${ }^{29}$ FERNANDEZ-GALIANO y DE CASTRO CID, Lecciones de Teoría del Derecho y Derecho Natural, Madrid 1995, pp. 421 ss.

${ }^{30}$ FERNANDEZ-GALIANO y DE CASTRO CID, Lecciones de Teoría del Derecho..., op. Cit., p. 422 n. 2

${ }^{31}$ H. POTTER, Historical introduction to English Law, London 1958.

${ }^{32}$ Según GARCIA GARRIDO, el Common Law fue desde el principio un Derecho positivo, aunque se considerara un Derecho Consuetudinario no escrito, mientras el Derecho Romano renacido en las Universidades era un Derecho ideal y culto. GARCIA GARRIDO, Derecho Romano Privado, op. Cit., pp. 56 y ss.
} 
pone en juego un sistema flexible, más orientado al casuismo práctico que a una realidad legal o la aplicación estricta de la norma codificada y técnica. Ello sin olvidar, que la propia elaboración y preparación jurídica anglosajona es eminentemente casuística, tomada de los casos que la realidad proporciona.

"El sistema del Common Law es un prototipo de un sistema de derecho judicial, o de derecho jurisprudencial. En realidad, es el mismo sistema del Derecho romano clásico, o al menos de los sistemas surgidos en la Europa accidental con la recepción, los cuales también fueron sistemas de derecho jurisprudencial. Sin embargo, no se pueden identificar los sistemas de derecho judicial con los de sistema jurisprudencial, sino que conviene distinguir entre unos y otros ${ }^{33}$.

\section{La Recepción Del Derecho Romano En Inglaterra: Contradicciones, Influencias,} $\underline{\text { Similitudes Y Diferencias }}$

La recepción del Derecho Romano en Inglaterra se caracterizó por la existencia de una serie de contradicciones, influencias, similitudes y diferencias de las que breve y casi telegráficamente vamos a ocuparnos.

\section{Contradicciones}

a.

Resistencia a la penetración del Derecho Romano en la Edad Media, hasta el punto que el Rey Esteban II en 1151 prohíbe su enseñanza ${ }^{34}$. La enseñanza del Derecho Romano fue prohibida por Esteban II, en Inglaterra ${ }^{35}$. Y esta prohibición fue más temprana y reiterada que el resto de Europa. Lo que prueba que existía pues, otro derecho que había que defender contra el romano ${ }^{36}$, el cual debería de estar plenamente desarrollado -o al menos no tan fragmentario-.

b. Influencia intensa en materias del Procedimiento Civil y en los Principios Jurídicos, como ocurría con la Equity $^{37}$ anglosajona. La práctica jurídica sobrevive en las Islas, incluso después de abandonada por los

\footnotetext{
${ }^{33 *}$ La distinción entre el derecho judicialy el derecho jurisprudencial forma parte de uno de los presupuestos metodológicos de la conversación jurídica, y se remonta a la diversa forma de llevar acabo la recepción del Derecho Romano en Inglaterra y en el resto de la Europa occidental con algunas diferencias. Así, mientras la recepción introdujo en todas partes, una jurisprudencia letrada que dio lugar a un reconocimiento desmesurado de la jurisprudencia clásica, revistiendo de una importancia extraordinaria la opinión de los juristas clásicos, en Inglaterra se llegó a la conclusión que había que limitar dicha fuerza, frente a los que mantenían la flexibilidad del sistema tradicional". JOSÉ LUIS DE LOS MOZOS, "El sistema del COMMON LAW" desde la perspectiva jurídica española", $R D P$, ABRIL 1983. p. 323.

${ }^{34}$ Vid. Nota 25.

${ }^{35}$ KOSCHAKER, Europa y el Derecho..., op. Cit..., p.307 ss.

${ }^{36} \mathrm{KOSCHAKER}$, Europa y el Derecho..., op. Cit., p.308: "La resistencia inglesa frente al Derecho Romano se debe exclusivamente al estamento de juristas. Aceptarlo en la forma en que le dieron glosadores y comentaristas hubiera significado para los ingleses permutar su derecho de juristas por otro también de juristas".

${ }^{37}$ Con el término Equityse designa el sistema jurídico que se contrapone al Common Law, y que se aplica en la Court of Chancery o Cancillería de la Corte. GARCIA GARRIDO, Derecho Privado Romano, op. Cit,. p. 57.
} 
romanos, aunque también fue conocida por la intervención del monje lombardo Lafranch ${ }^{38}$, que llegó a Inglaterra en 1042 acompañando a Guillermo el conquistador. Dicho monje sentó las bases del Common Law.

En Inglaterra, el derecho sea particular o regio descansa sobre la base del derecho común, o sistema del Common Law en cuyo conocimiento se habían formado los juristas ingleses, funcionando al modo de un derecho científico o racional. En la práctica, era un derecho que ponía en ejecución un sistema flexible, orientado al casuismo de la realidad cotidiana. Sin olvidar, que la propia especulación jurídica era eminentemente casuística ${ }^{39}$.

Influencias

Por otra parte, es de destacar una serie de influencias:

a. Influencia histórica: La ocupación de Britannia comienza a principios del 54 a. C. con Julio Cesar que desembarca en las Islas para acabar con los celtas y sometiendo algunos pueblos del sur, aunque la conquista se culmina por Claudio, un siglo después.

En el 410 d. C. Estilicón ordena la retirada de las legiones de Britannia para la defensa de Roma, con lo cual desaparece el control del territorio por los latinos, aunque permanecen algunos vestigios, incluso en el lenguaje, como el término latino "Castra", del cual deriva "Chester", o "Cester" (campamento o castillo). Así mismo la idea de Estado, la influencia del cristianismo o el propio Derecho Romano, si bien el anterior al codificado por Justiniano.

b. Influencia de la escuela de Bolonia, a partir del Siglo XI. Vaccarius, estudiante de Bolonia que en 1145 obtuvo la cátedra de Derecho Romano en Oxford, llegó a poner en entredicho el Derecho Real o Derecho tradicional inglés, hasta que en 1151 el rey Esteban prohibió sus enseñanzas y la del Derecho Romano ${ }^{40}$. Escribe un resumen de la obra justinianea orientado a los jóvenes que sin medios de fortuna no podían hacerse con las caras obras jurídicas. Se le denominó el Liber Pauperum.

\footnotetext{
${ }^{38}$ LAFRANCH, llegó a ser nombrado arzobispo de Canterbury y canciller del rey en 1070. CAMACHO EVANGELISTA, EI Derecho romano y su recepción,...op. cit,. p. 399.

${ }^{39}$ Según De los Mozos: "El sistema del Common Law es un prototipo de un sistema de derecho judicial, o de derecho jurisprudencial. Es el sistema del Derecho romano clásico, o de los sistemas surgidos en la Europa occidental con la recepción, los cuales también fueron sistemas de derecho jurisprudencial. Sin embargo no se pueden identificar los sistemas de derecho judicial con los de sistema jurisprudencial, sino que conviene distinguir entre unos y otros. La distinción entre el derecho judicial y el derecho jurisprudencial forma parte de uno de los presupuestos metodológicos de la conversación jurídica, y se remonta a la diversa forma de llevar a cabo la recepción del derecho romano en Inglaterra y en el resto de la Europa occidental. Mientras la recepción introdujo en todas partes una jurisprudencia letrada que dio lugar a un reconocimiento desmesurado de la jurisprudencia clásica, revistiendo de una importancia extraordinaria la opinión de dichos juristas clásicos, por ello, en Inglaterra se llegó a la conclusión que había que limitar dicha fuerza, frente a los que mantenín la flexibilidad del sistema tradicional". DE LOS MOZOS, "EISISTEMA DE COMMONLAW"desde la perspectiva jurídica española", RDP, abril 1983, pp. 323 ss.

${ }^{40}$ KOSCHAKER, Europa y el Derecho..., op. Cit., p. 315.
} 
No obstante, y a pesar de otra posterior prohibición en 1234, por el rey Enrique III, el Derecho Romano se sigue estudiando, si bien por la vía del Derecho Canónico que va a influir sobre el Common Law.

c. Influencia de los propios autores ingleses: Glanvill ${ }^{41}$ y Bracton ${ }^{42}$, éste último nombrado juez en $1245, \mathrm{y}$ que por motivos de unas discrepancias con el rey Enrique III se retirará al campo donde escribe su obra "Tratado de las leyes y las costumbres del reino de Inglaterra". Se trata de un libro de práctica de los tribunales, basado en las Instituciones de Justiniano (D. de cosas, de las personas, obligaciones, acciones procesales), si bien la reacción gremial y clasista de los jueces ingleses hacia el Derecho Romano por considerarlo un derecho imperial, hace que el Common Law termine imponiéndose a pesar de ser un derecho rudimentario, tosco y rígido ${ }^{43}$.

d. La intervención real. Sin embargo y a pesar de estos antecedentes, en el Siglo XVI es el siglo del Derecho Romano, el cual se impone con Enrique VIII. Dicho Rey nombra los regii professores, que enseñaran el Derecho Romano (título con el que se conocen en las universidades inglesas, aun hoy día, a los profesores de Derecho Romano).

Por otra parte, se crea el Court of Admiralty (el Tribunal Real de la Armada) con la misión de juzgar los delitos de piratería, comercio y navegación, pero que utilizará para ello el Ius Mercatorum, con base en el Derecho Romano. Koschaker considera que los tribunales de la época (Star Chamber, Council, Court of Request) emplean a juristas del "College of Doctors of Law exercert in the ecclesiastical and Admiralty Court", prevaleciendo finalmente el Common Law, el cual es acogido por el propio Parlamento.

Koschaker $^{44}$, recoge la controversia entre el Derecho Romano y el Derecho Inglés en lo referente a la Teoría del Derecho. John Austin, filósofo utilitarista seguidor de Bentham, llega a defender la codificación del derecho privado inglés sobre la base del Derecho de Pandectas Alemán. Summer Maine en Cambridge y Maitland, sobre todo debido a la influencia de Brunner y Otto Von Gierke, patrocinan el Derecho Romano como "lengua de la jurisprudencia Universal"45.

Similitudes

\footnotetext{
${ }^{41}$ GLANVILL, "Tractatus de legibus et consuetudinibus regni Angliae, qui Glanvilla vocatur", en 1187, probablemente en Oxford. ${ }^{42} \mathrm{La}$ obra de BRACTON tiene igual nombre, "Tractatus de Legibus et consuetudinibus regni Angliae, libri quinque" fue escrita en 1250 en Oxford. Posteriormente fue conocida con el nombre abreviado de "De Legibus Angliae". Obras ampliamente destacadas por CANNATA, Historia de la Ciencia Jurídica, pp. 150, 168, y 231. cit. PANERO en "El Derecho Romano en ..., op. Cit. P. 136, n. 58.

${ }^{43}$ Precisamente debido a su rigidez, el tribunal del Lord Canciller (Court of Chancery), tiene la necesidad de acudir a la -Equity como medio de a atender a la resolución de cada caso.

${ }^{44}$ KOSCHAKER, Europa y el Derecho Romano..., op. Cit, p. 316.

${ }^{45}$ Decía Koschaker, que "el Derecho Anglo americano no es susceptible de ser recibido, ya que no puede concebirse siquiera que millares de volúmenes que contienen todavía mayor número de sentencias, todo ese derecho casuístico del Case Law, pueda constituir base adecuada para el nuevo derecho". KOSCHAKER, Europa y el Derecho..., op.cit,, p. 235 op. Cit. pp. 240-242.
} 
1. En materia de procedimiento civil, romanistas como Buckland, Mc Nair ${ }^{46}$, Clark, Peter, Pringsheim, o procesalistas como Gorla destacan el paralelismo entre el procedimiento romano, y el procedimiento inglés. Así ocurre con:

a. $\quad$ Fase in iure, es equivalente a la "Issue Making Stage" (sistema procesal inglés)

b. $\quad$ Fase apud iudicem, in iudicio, es equivalente al "Trial".

c. $\quad$ Fase de la "Interrogatio in iure" es equivalente al "Pre-Trial" (o fase de encuestas) o fase previa. Se trata de una fase donde la averiguación y descubrimiento de los hechos, se lleva a cabo por el procedimiento de interrogatorios o encuestas ("discovery by interrogatories").

d. El descubrimiento por los hechos, en el sistema sajón es "Discovery of facts" (Los hechos son los que hablan).

2. Apreciación de la prueba testifical. En nuestro sistema judicial, y en el Derecho Canónico que es similar a en cuanto a la validez y número de testigos, se rige por los siguientes principios:

a. Testis unum testis nullos [testigo único, testigo nulo].

Por tanto, para poder ser utilizados como medio de prueba, han de coincidir en su declaración al menos dos testigos. En cambio en el Derecho Romano, la apreciación de la prueba testifical lo es por la sinceridad o calidad que ofrecen los testigos, mas que por el número de los mismos, como en el Derecho Inglés.

b. In ore duorum vel trium statr veritas [En lo dicho por dos, la verdad la establece un tercero].

El proceso inglés es similar al Romano Clásico, ya que tanto en uno como en otro sistema, un solo testigo -testigo de cargo o Witness of testimony- basta para fijar la validez de la declaración, a igual que a la inversa un testigo puede eximir de los cargos -testigo de descargo-. Así ocurre en el Derecho Romano, como se demuestra en D.22.5.21.3:

Si testes omncs eiusdem honestatis et existimationis sint, et negotii qualitas ac iudicis motus cum his concurrit, sequenda sunt omnia testimonia; si vero ex his quidam eorum aliud dixerint, licet impari numero, credendum est; sed quod naturae negotii convenit, et quod inimicitiae aut gratiae suspicione caret; confirmabitque iudex motum animi sui ex argumentis, et testimoniis, et quae rei aptiora, et vero proximiora esse compererit; non enim ad multitudinem respici oportet, sed ad sinceram testimoniorum fidem, et testimonia, quibus potius lux venitatis assistit ${ }^{47}$.

Texto donde en caso de confluencia tanto en honestidad como en la apreciación de la honradez de los

\footnotetext{
${ }^{46}$ A.D. Mc NAIR, "Roman Law and Common Law",2a ed. Cambridge 1952.
}

${ }^{47} \mathrm{Si}$ todos los testigos fueran de la misma honradez y estimación, y con ellos concurren tanto la calidad del negocio como el sentir del juez, se ha de estar a todos los testimonios; pero si algunos de ellos hubieren dicho cosa distinta, se ha de dar crédito aún al número desigual; pero en lo que conviene con la naturaleza del negocio, y está exento de sospecha de enemistad ó de favor; y el juez confirmará con los argumentos y los testimonios la inclinación de su ánimo, y lo que hallare que es más adecuado al asunto, y más aproximado a la verdad; porque no debe atenderse a la multitud, sino a la sincera fe de los testimonios, y a los testimonios en que más bien se halla la luz de la verdad. Traducción GARCIA DEL CORRAL, Cuerpo de Derecho Civil Romano. Tomo II, p. 111. vol.10, no. 01, Rio de Janeiro, 2017.pp. 291-316 
testigos se ha de dar credibilidad a la coincidencia de los testimonios de dichos testigos, pero en caso que ello no sea así por sospechar de enemistad o de la falsedad, más que a la cantidad de los testimonios, el juez debe de atenerse a la sinceridad o a la verdad del testimonio. Con ello se coincide con la máxima legal inglesa que "El valor de la prueba testifical lo es por ella misma en razón de la sinceridad de los testigos y no por el número de ellos". Ya que puede haber varios testigos, ahora bien, si todos mienten se invalidaría la declaración. Por ello, en el Derecho Ingles, la veracidad de la declaración de los testigos o consideración de testigo cualificado requiere de un examen previo de su idoneidad o su apreciación por el jurado.

3. La ambivalencia que en el Derecho Romano se da entre el Ius Honorarium y el Ius Civile, se puede encontrar en el Derecho Inglés, entre la Equity y el Common law, a igual que sucede con las figuras del Praetor romano y el Chancelot Inglés. Por ello, es con la jurisprudencia anterior a la recepción del Derecho Romano, con la que hay que conectar y engarzar al Common Law, por cuanto que no está de más recordar que en su origen, tanto su aceptación como a su rechazo obedece a las luchas entre la corona y la nobleza ${ }^{48}$.

\section{Diferencias}

1. En el campo de los Derechos Subjetivos. Para el Derecho Romano, los derechos subjetivos son la causa del ejercicio de la acción procesal, si no existe ius no existe la actio que los protege. En el D. Inglés, los derechos subjetivos lo son en cuanto son declarados y obtienen su protección a través del sistema procesal, por tanto y hasta que no son formulados por el juez, no se concretan en una norma o criterio interpretativo.

2. Por el Sistema Judicial. El Derecho Romano, al menos el de la época clásica, es el sistema prototipo del llamado Derecho Jurisprudencial, en tanto que el pretor romano crea Derecho para cada caso concreto. En el Derecho Romano, la jurisprudencia tiene otro significado muy diferente del actual, ya que sus maneras de expresión son también diferentes, aludiendo todas ellas a diversas formas de entenderla: Responsa Prudentium, Edictum Praetorium, los Rescriptos del Príncipe... A igual que en el sistema romano, se ofrece un sistema de fuentes mucho más complejo: Ius Civile, Ius Honorarium, Mores, Leges... ${ }^{49}$ El pretor tiene imperium mediante el cual se concede valor a las decisiones o responsa que decidan en el litigio. Por el contrario, el sistema Anglosajón tradicional, es un sistema de tipo judicial ya que las decisiones alegadas son tomadas en cuenta en cuanto se basan o fueron aceptadas por un juez anterior independientemente de su acierto.

${ }^{48}$ H. POTTER: "Historical introduction to English Law.., op. Cit.

${ }^{49}$ KUNKELL: "Historia del Derecho Romano", Barcelona 1965, p. 83. ALVAREZ: "La Jurisprudencia Romana en la Hora presente",MADRID 1966. 
Es el Sistema de Case Law en el cual el juez es la ley (the judge is law), representado una desviación respecto al Sistema Romano a igual que ocurre con los otros derechos continentales. El sistema judicial, tan pendiente siempre del precedente, opera de una forma más mecánica, con lo que se llega a una cierta fosilización del sistema, y desnaturalizando la función judicial, según $\operatorname{Esser}^{50}$, esta necesidad de estar siempre pendiente del precedente, es más peligrosa aunque la rigidez de los textos legales, y en definitiva diferencia al sistema del Derecho Judicial o Sistema del Case Law, del llamado Derecho continental.

3. Por el distinto valor asignado a la jurisprudencia como sistema de fuentes.

El Sistema del Case Law se contrapone al sistema latino-Continental, porque en el sistema del Case Law el significado de las relaciones entre las fuentes del Derecho y la Jurisprudencia es distinto. En el sistema anglosajón, las fuentes del Derecho se definen después de su realización, no antes de ella como en el derecho continental $^{51}$.

Además la Jurisprudencia en el sistema del Case Law, tiene una doble función:

1) Realiza el Derecho.

2) Esta realización del derecho, consolida y prueba la propia existencia del derecho: La Jurisprudencia crea el derecho.

En el sistema continental, la jurisprudencia complementa al sistema de fuentes ya previamente establecido en la ley, la costumbre o los principios del Derecho, asignándole la misión de interpretar y aplicar la ley pero no la de "crear derecho" 52 .

En los sistemas jurídicos continentales, la Codificación rompe con el sistema casuístico anterior, alterando el equilibrio entre los diversos factores que intervienen en el derecho y dando un predominio absoluto a la ley, con lo cual se alejan de un sistema de derecho jurisprudencial.

En conclusión, las diferencias de método entre ambos sistemas tienen lugar y pueden ser explicadas por la diversa forma de llevar a cabo la recepción del Derecho Romano.

\section{Influencia Histórica Del Derecho Romano En Alemania}

\footnotetext{
${ }^{50}$ J. ESSER: "Principio y Norma en la elaboración jurisprudencial del Derecho", trad. española 2º ed., Barcelona 1978. p. 15 ss. ${ }^{51}$ En el sistema continental, la jurisprudencia complementa al sistema de fuentes ya previamente establecido en la ley, la costumbre o los principios del Derecho, asignándole la misión de interpretar y aplicar la ley pero no la de "crear derecho". Así se puede ver en el artículo $1^{\circ} .6$ del Código Civil y Y sobre todo cuando en el artículo $1^{\circ} .7$ del Código Civil español donde obliga a que "los Jueces y Tribunales tienen el deber inexcusable de resolver en todo caso los asuntos de que conozcan ateniéndose al sistema de fuentes establecido".

${ }^{52}$ Así se puede ver en nuestro Derecho en el artículo 1․ 6 del Código Civil: "La Jurisprudencia complementará el ordenamiento jurídico con la doctrina que, de modo reiterado, establezca el Tribunal Supremo al interpretar y aplicar la ley, la costumbre y los principios generales del Derecho".

Y sobre todo cuando en el artículo $1^{\circ} .7$ del Código Civil español donde obliga a que "los Jueces y Tribunales tienen el deber inexcusable de resolver en todo caso los asuntos de que conozcan ateniéndose al sistema de fuentes establecido".
} 
La Germania de la edad Antigua apenas si había sufrido más que una ligera romanización limitada cuando más a la parte occidental ${ }^{53}$. La gran dispersión en los conocimientos y el oscurantismo propio de la Edad Media impidieron que existiera un derecho unitario. Entre los pueblos germánicos se conoce el Derecho de las estirpes (sippe) o de los linajes, con una gran diversidad entre los derechos troncales y nacionales. Así son de citar leyes como la ley Sálica, Ribuaria o Ripuaria, la lex Alemanorum, lex Baverienses, Sajones, Frisones,...etc.

La idea Europeísta la encarna a partir del año 800 el Emperador Carlomagno, cuando es coronado como Emperador del Sacro Imperio Romano-Germánico, a imagen y semejanza de la monarquía universal. Aunque en 887 se disuelve el imperio franco-germánico al coronarse Arnulfo de Carintia rey de Alemania.

El Derecho en su aplicación hasta ese momento, gira sobre los dos grandes principios siguientes:

a. $\quad$ El principio de personalidad de las leyes: Las leyes se dictan para las personas y acompañan a ellas allí donde se encuentren. Es el principio típicamente romano: Allí donde se encuentre un ciudadano romano, allí están las Leyes de Roma.

b. Principio de territorialidad: Las leyes se dictan para el territorio y carecen de efectividad fuera del mismo. Es el principio germánico de la aplicación del derecho: Fuera del territorio donde se aplica, la ley no puede ser exigida ${ }^{54}$.

En Alemania, este Principio de Territorialidad y la dispersión de las leyes locales (como son los derechos municipales, de las que son buen ejemplo, las Flores de Magderburgo, Meissen, Viena), leyes feudales, señoriales, de prerrogativas a la nobleza, etc... Impiden la aparición de un derecho Unificador.

Aunque se suele señalar entre los siglos XII y XV, y concretamente en el año 1495 con la promulgación de la Ordenanza del Tribunal Cameral el comienzo de la Recepción del Derecho Romano ${ }^{55}$.

No obstante, entre los S. XIII/XIV aparecen compilaciones privadas de libros de derecho (Rechtsbücher), como son:

a. El Espejo de Sajonia (Sachsenspiegel) debido a Eike von Repkow (1215-1253).

b. El Espejo del Pueblo Alemán (Spiegel Deustcher Lente), entre 1235-1275

c. Libro del Derecho Territorial y feudal (Landrechts und Lehrrechtsbuch), o el libro del Derecho Imperial (Kaiserrechtsbuchs).

d. El Espejo de Suabia (Schawabenspiegel).

e. $\quad$ El libro del pequeño derecho imperial (das Kleine Kaiserrechts).

Frente a ello, el Derecho Romano aparece como un derecho integrador, un derecho que obedece a un sistema completo y total, que no totalitario, que en su versión justinianea va a suplantar al propio y local Derecho

\footnotetext{
${ }^{53}$ PANERO, El Derecho Romano en la Universidad..., op. Cit., p. 157.

${ }^{54}$ Por ejemplo, el artículo 8.1 del Código Civil Español: "... las leyes penales, las de policía y las de seguridad obligan a los que se hallen en territorio español". (Es de tener presente que el párrafo 20 fue derogado por la Ley de 7 de Enero de 2000, de LEC). vol.10, no. 01, Rio de Janeiro, 2017.pp.291-316 
Alemán. A ello ayuda la idea que los Emperadores Alemanes se consideran Emperadores del Sacro Imperio Romano-Germánico ${ }^{56}$. Es la idea de la renovatio imperii ${ }^{57}$.

La influencia de Bolonia por otra parte, donde los estudiantes estaban distribuidos por nationes, (así los alemanes eran la natio teutónica) y su difusión va a propiciar la influencia del Derecho Romano como un Derecho Universal. El Derecho Romano se convierte con ello en la ratio scripta. Complemento de ello es la influencia de la Iglesia y del Derecho Canónico, de donde se van a formar los tribunales arbitrales ${ }^{58}$. No es extraño que los tribunales alemanes apliquen el Derecho Romano. Incluso en 1495 se crea el Tribunal Cameral del Imperio compuesto de Doctores Iuris y nobles los cuales van aplicar el Derecho Común Imperial.

Finalmente, se crean los Tribunales Territoriales que giran consultas sobre casos difíciles a las propias Facultades de Derecho, con lo cual en esta época el veredicto emitido por una Facultad de Derecho es equivalente a las sentencias de los tribunales ${ }^{59}$.

\section{Influencia Historica Del Derecho Romano En La Jurisprudencia Medieval, En Francia Y En España}

Frente a una jurisprudencia académica, aparece una jurisprudencia basada en una labor interpretativa y orientadora, como fue la Jurisprudencia del Parlamento de París, de las Reales Audiencias de España y de la América Española. Es con la jurisprudencia anterior a la recepción con la que hay que conectar y engarzar al Derecho común, que no está de más recordar que como ya vimos, en su origen obedece a las luchas entre la corona y la nobleza ${ }^{60}$.

\section{$\underline{\text { La Recepción Del Derecho Romano En Francia }}$}

En realidad, en Francia el conocimiento y aplicación del Derecho Romano no quedó interrumpido, ya que se continúa durante la Edad Media, a pesar de la caída del Imperio Romano, gracias a obras como el Breviario de Alarico. Posteriormente, la recepción del Derecho Romano llega de las manos de los estudiantes de Bolonia a partir de los siglos XII y XIII.

\footnotetext{
${ }^{55}$ PANERO, El Derecho Romano en la Universidad..., op. Cit., p. 157.

${ }^{56}$ Otra idea de P. KOSCHAKER es que el derecho romano es el Derecho Natural de la Cristiandad occidental, el cual no llegó a cuajar en un "Privaterechtsgeschichte".

${ }^{57}$ Es decir la restauración del imperio de occidente que acompañará durante mil años el desenvolvimiento de la historia europea, hasta los tiempos modernos ( DE LOS MOZOS, "El Derecho Común y el nacimiento de Europa", RCDI, 613, pp. 2525).

${ }^{58}$ VINOGRADOFF, El Derecho Romano en la Europa Medieval. Proceso formativo, Francia, Inglaterra y Alemania, Barcelona 2000, pp. 43-44.

${ }^{59}$ WIEACKER, Historia del Derecho Romano en la Edad Moderna, pp. 112-113.

${ }^{60}$ H. POTTER, Historical introduction to English Law, 4a Ed., London 1958.
} 
Las Universidades francesa continúan sus enseñanzas romanísticas, bien a través de los estudios de Teología y del Derecho Canónico (como la Universidad de Paris), bien del propio Derecho Romano (como Montpellier, Toulouse, Orleans).

Según Vinogradoff ${ }^{61}$, es obligado al estudiar la recepción y el régimen jurídico de Francia partir de la existencia de dos zonas de influencia bien diferenciadas:

a. $\quad$ El Sur de Francia (o Le pays de Droit ecrit), donde rige el propio Derecho Romano.

b. $\quad$ El Norte de Francia (o Pays de Droits coutumiers), o derecho de costumbres ${ }^{62}$.

a) En el Sur de Francia o Le pays de Droit ecrit, se presenta una larga tradición de estudio de los textos romanos que arrancan de los siglos V y VI con la Lex Romana Wisigothorum y la Lex Romana Burgundionum que prepararon el camino para la recepción del Derecho Romano. En esta zona, son de destacar entre los textos jurídicos, obras como Exceptiones Petri (o Exceptiones Legum Romanorum, resumen de textos del Digesto y del Codex Justinianeo), el Brachylogus Iuris Civilis (donde se recogen las enseñanzas del Derecho Romano siguiendo el orden y el Sistema de la Escuela de Bolonia postirneriana), y Lo Codi (publicado en Arlés, en el 1149), que contiene un resumen del Derecho Romano Justinianeo escrito en lengua romance-provenzal. A ellos le siguen, la Summa Trecensis o Summa al Codex de Irnerio de Peroggia, libro de usos de Tribunales ${ }^{63}$, de difusión también en Francia, con origen en las citadas ciudades Italianas.

b) En le pays de Droits coutumiers, el Derecho Romano se vio frenado por el rechazo de la monarquía, que consideraba que era un derecho del Imperium (y en esos momentos el Imperio era el Sacro Imperio Romano-Germánico) y ello a pesar de que el propio Derecho Romano habia servido de base al crecimiento del poder real, en base al principio Rex Franciae est imperator in regno suo, como lo recuerda Koschaker ${ }^{64}$. Por ello, frente a una jurisprudencia académica, propia de los comentaristas y humanistas versados en los estudios del Derecho Romano, aparece una jurisprudencia basada en una labor interpretativa y orientadora, como fue entre otras, la Jurisprudencia del Parlamento de París.

Por otra parte, paradójicamente la propia jerarquía eclesiástica también se opone al estudio del Derecho Romano porque ve en ello un desplazamiento de los estudios teológicos lo que puede alejar de su estudio a clérigos y religiosos ${ }^{65}$. Al final, consigue que se prohíba su enseñanza.

\section{La Recepción Del Derecho Romano En España}

\footnotetext{
${ }^{61}$ VINOGRADOFF, Derecho Romano en la Europa medieval; proceso formativo en Francia..., op. Cit., pp. 75-87.

${ }^{62}$ Donde rige un derecho de costumbres, pero que acepta el Derecho Romano.

${ }^{63} \mathrm{Libro}$ excelente que posiblemente fuera redactado por el monje Rogelio,y según VINOGRADOFF permitía conocer la práctica y el uso del Derecho Romano en Provenza. Vinogradoff, Derecho Romano en la Europa medieval..., op. Cit., p. 63

${ }^{64}$ KOSCHAKER, Europa y el Derecho Romano..., op. Cit., p. 128 ss.
} 
La recepción del Derecho Romano en España presenta características especiales debido al conocimiento y practica en nuestro país del derecho romano vulgar, y a la vigencia de las leyes romano bárbaras ${ }^{66}$. Es cierto, que la gran variedad y abundancia de trabajos ${ }^{67}$ sobre la llamada “Recepción del Derecho Común”, no es propiamente un objeto de la reflexión romanista por ello nos limitaremos a enunciar algunos datos sobre la presencia del Derecho Romano en la Península. Son de destacar:

a) Código de Eurico (del año 467), supletorio del Codex Theodosianus el cual tiene como finalidad su adaptación práctica (según Merea, Iglesias, o Ferreiros). Se conserva en el llamado Palimpsesto de Paris $^{68}$.

b) La Lex Romana Visigothorum o Breviario de Alarico (del año 506), que es una compilación de Leges y Iura. Su contenido se basa en textos del Codex Theodosianus, el Epitome de Gayo, Pauli Sententiae y fragmentos del Codex Gregorianus, Codex Hermogenianus, y escritos de Papiniano.

c) Codex Revisus, obra de Leovigildo del año 580 .

d) Liber Iudiciorum de Recesvinto del año 654 ${ }^{69}$. Posteriormente fue denominado Fuero Juzgo por Fernando III, el Santo.

e) Etymologicum (o "Las Etimologías" de San Isidoro de Sevilla, +636), obra enciclopédica basada en el código Teodosiano y en la obra de Justiniano. Fue una obra muy utilizada para la posterior de "las Decretales" de Graciano (1140).

Es de destacar la influencia de los autores hispánicos en Bolonia, sobre todo a partir de la fundación por el cardenal Egidio de Albornoz en 1364 del "Colegio di Spagna" en Roma. Esta doble influencia va a desembocar en la preparación de gran número de juristas procedentes de Bolonia, los cuales a va ser nombrados profesores en las nuevas Universidades, como la de Salamanca (fundada por Alfonso IX en el 1220) y que posteriormente van a influir en la difusión y conocimiento de las obras jurídicas.

a) Las Siete Partidas de Alfonso X el Sabio, la gran obra base de la recepción del Derecho Romano en España. Toma diversas influencias de la Glosa Magna de Acursio, la Suma, y el Codex de Azón.

\footnotetext{
${ }^{65}$ De ahí las bulas del papa Honorio III (la "Super Specula..." de 1219), y la de Inocencio IV ("dolientes..." en 1254).

${ }^{66}$ Lógicamente el contenido de la presente cuestión es materia de la asignatura de Historia del Derecho Español. Pero como decía FUENTESECA, P., sería necesario revisar toda la historia del Derecho Español para conocer la influencia romana. FUENTESECA, P., Historia del Derecho Romano, Madrid 1987, p. 318.

${ }^{67}$ Solo y por citar a titulo de ejemplo, de entre la rica y extensa bibliografía, vid. IGLESIA, La Recepción del Derecho Común: estado de la cuestión e hipótesis de trabajo, Actas II Simp. Internac. Sobre Derecho Común y Cataluña, Barcelona 1992. FONT RIUS, La Recepción del Derecho Romano en la península iberica durante la Edad Media, Actes des Journées Internacionales, Montpellier 1966. HINOJOSA, Estudios de síntesis, Madrid 1974. PEREZ MARTÍN, El estudio de la Recepción del Derecho Común en España, I Seminario de Historia del Derecho y Derecho Privado, Bellaterra 1985. GARCÍA A., La Recepción del Derecho Romano en España hasta el siglo XVI, Estudios Jurídicos in memoriam del prof. A. Calonge, I, Salamanca 2002, pp. 421434.

${ }^{68}$ Reconstruido por D’ORS.
} 
b) El Ordenamiento de Alcalá, de 1348 donde se reconoce como fuente, el valor subsidiario del Derecho Romano.

c) Las Leyes de Toro de 1505, donde se prohíbe alegar leyes romanas por vía directa, sino a través de la forma indirecta de haber sido recogidas o mencionadas en el contenido de las Partidas.

d) La Nueva y la Novísima Recopilación.

e) y el Código Civil Español de 1889, donde se culmina la obra de la codificación en nuestra patria.

En cualquier caso y como nos recuerda Iglesias ${ }^{70}$, "la atención de los historiadores y de los juristas se ha centrado básicamente, en señalar de manera aproximada el parentesco entre las soluciones recogidas en las colecciones de Derecho Propio y el Derecho Romano justinianeo, a partir en muchos casos de la creencia en unos principios jurídicos identificables y que pueden vincularse al Derecho Romano, Derecho Germano, o Derecho Canónico...”.

\section{Influencia Histórica Del Derecho Romano En Algunos Casos Exóticos}

Koschaker $^{71}$, al mencionar los lugares en donde en mayor o menor medida el Derecho Romano rige o ha regido recientemente recoge a Escocia, Sudáfrica, Ceilán, Grecia y la Guayana Inglesa, aunque comete el imperdonable error de olvidar a Navarra, Cataluña y Baleares ${ }^{72}$. En el campo del Derecho privado la influencia del Derecho Romano se percibe clara en los códigos civiles europeos accidentales.

Se han encontrado no solo vestigios, sino influencias muy directas en sistemas tan dispares como lo son, no solo en el japonés, sino también el chileno, Brasil, incluso en la India.

\section{El Caso de Japón}

Curiosamente el Derecho Romano tuvo una gran influencia en Japón, donde en el Siglo XIX se formó una comisión para el estudio del Derecho civil de los distintos reinos europeos, de cara a extraer importantes datos para proceder a su codificación civil, como iniciativa cara la modernización y armonización con el mundo

\footnotetext{
${ }^{69}$ Aunque hubo una 2a edición de Ervigio en el 681.

${ }^{70}$ IGLESIA, La recepción del Derecho Común..., op. Cit., p. 274.

${ }^{71}$ KOSCHAKER, Europa y el Derecho ..., op.cit. p. 235

${ }^{72}$ KOSCHAKER, Europa y el Derecho Romano, op. Cit., p. 114-115 Y 212-213) al mencionar los lugares en donde en mayor o menor medida el derecho romano rige o ha regido recientemente recoge a Escocia, Sudáfrica, Ceylán, Grecia y la Guayana Inglesa, aunque comete el imperdonable error de olvidar a Navarra, Cataluña y Baleares. El desconocimiento es común a parte de la romanística, así GUARINO (L'esegesi delle fonti del Diritto romano, Nápoles 1968, p. 8) desconoce la existencia de regiones españolas donde el derecho romano ha subsistido o tiene vigencia actual. Lo curioso es que alude al limitato vigore del Derecho romano en Ceylán, Escocia, Grecia y Sudáfrica; lugares bastante más alejados de Nápoles que nuestras regiones forales. Este detalle resulta curioso cuando como reconoce VALIÑO que hace la recesión critica al libro de GUARINO (AHDE, 38(1968) p. 699) cita dos páginas antes precisamente a NAGORE ("Il vigore del Diritto romano in Navarra", Bol. Inf. Ist. Giur. Span. in Roma, 40-43 (1963, pp. 18-23).
} 
occidental. Dicha comisión fue enviada a distintos países europeos entre ellos en España y Alemania. Esta Comisión toma contacto con García Goyena en 1851, donde por aquel entonces se estaba elaborando el anteproyecto de código civil -antecedentes del código civil español de 1889- y posteriormente, ya en la Alemania de Bismack con el código prusiano de 1870, precedente del BGB en 1900, que fue traducido al japonés con una gran celeridad. Tanta, que entró en vigor antes que el propio código alemán. Con ello, Japón introdujo un sistema jurídico occidentalizado a fines del siglo XIX, cuando el Derecho civil y el Derecho procesal civil ya se habían separado y su codificación se había completado en las potencias europeas más importantes. Esta particularidad temporal dio su carácter peculiar a los estudios de Derecho romano en Japón ${ }^{73}$.

\section{El Caso De La India}

Según James Manus Mc.Caffery ${ }^{74}$, "En 1817, Mr. Dart W.K. un americano de Nueva York, tomó parte en la redacción de un código civil o código de procedimiento civil basado en las leyes españolas, las cuales a su vez se basaban en el Derecho Romano. Fracasó en su intento de colocarlo en Nueva York... Pero fue adoptado por el Estado de Luisiana. El célebre aventurero E. Livingston, mandó una copia del texto al famoso filósofo utilitarista Jeremy Bentham, el cual a su vez mandó una copia a Lord Mc.Cauley -coronel inglés al mando de un regimiento-, que estaba a punto de irse a la India. Éste último, usó de esta obra como base del Código de la India, sin duda pensando en era lógico que así fuese, puesto que lo que se había preparado para usarlo en favor de la población indígena del Misisipí, nada mejor que destinarlo a figurar como estructura jurídica -según sus palabras-... a los "Indios" del Ganges y del Hoogley".

\section{EL DERECHO ROMANO COMO DERECHO COMUN EUROPEO}

Decía José Luis de los Mozos $^{75}$ que "La idea que ha acompañado durante más de 1.000 años a la historia europea es la restauración del imperio Romano de Occidente". En realidad, el Derecho Romano siempre ha sido

\footnotetext{
${ }^{73}$ Sobre la recepción del Derecho romano en Japón como parte de la modernización de la Era Meiji. Vid. Interesante el artículo de HAYASHI, TOMOYOSHI, El Derecho Romano y el Código Civil en el Japón Moderno: Sistemática, Propiedad y Copropiedad, Revista Chilena de Derecho 2009, 36, pp. 10 ss: "Cuando las clases de Derecho occidental comenzaron en 1874 en Tokio KaiseiGakko (que es la precursora de la Universidad de Tokio), la asignatura Derecho romano se enseñaba ya por un profesor inglés, William E. Grigsby. Desde entonces, el Derecho romano ha sido enseñado continuamente a nivel universitario en Japón y puede observarse una importante cantidad de investigación al respecto. Ha sido tratada como una materia separada y distinta del Derecho civil moderno, pero el diálogo entre ambas materias ha continuado hasta el hoy".

Disponible ss., en: http://www.redalyc.org/articulo.oa?id=177014521002, ISSN 0716-0747.

${ }^{74}$ JAMES MANUS MC.CAFFERY, NEW ORLEÁNS (LUISIANA), "La influencia de las leyes más lejanas en los ordenamiento más dispares" RDP, ABRIL 1987.

${ }^{75}$ Sobre esta materia DE LOS MOZOS, "El Derecho Común y el nacimiento de Europa", RCDI (68) 613, pp. 2523-2534. DE LOS MOZOS. "El sistema del COMMONLAW"desde la perspectiva jurídica española, RDP, abril 1983.
} 
un Derecho Común Europeo desde el siglo XII hasta el siglo XX ${ }^{76}$. En la doctrina ante la nueva realidad europea caben dos opciones:

1. Buscar la armonización del Derecho, tratando de lograr la realización de un derecho de juristas (juristenrechts).

2. O la unificación de los diversos sistemas europeos, buscando convertirlo en un derecho de burócratas (Bürokratrechts).

Es evidente que cada una de estas posturas tiene encendidos defensores y detractores. Pero lograr el objetivo de un Derecho Europeo integrador se requiere tener muy presente tanto los puntos en común, esto es, lo que nos une, como las diferencias entre diferentes sistemas jurídicos y ordenamientos dispares como corresponde a los derroteros de cada uno de los distintos países, que obedecen a una trayectoria histórica de los más diversos acontecimientos.

Para lograr el objetivo integrador, existen puntos en común:

a) Idénticos valores democráticos, vida parlamentaria, independencia judicial, régimen de libertades públicas, garantías del procedimiento, reconocimiento de la propiedad privada, reconocimiento de la autonomía de la voluntad en la contratación, similar concepción de la herencia, matrimonio, etc...

b) Principios jurídicos idénticos o muy semejantes, y la concepción del Derecho como aglutinante de la idea "Europa".

Pero también existen diferencias, entre otras:

c) Con el Common $\mathrm{Law}^{77}$, los conceptos de Trust, Equity, Implied Condition.

d) Con el Derecho continental, la distinta visión y conceptos de los derechos reales, propiedad, posesión que no son equivalentes.

e) Con los países latinos, así por ejemplo, Francia no acoge la teoría y doctrina del negocio jurídico (Geschäft). En el C.C. español, tampoco lo recoge como tal, aunque parecen aludir a él algunos de sus preceptos.

Los Códigos Civiles de origen latino o romanístico, como el Español o el Francés por regla general, no se ocupan de los hechos ni de los negocios jurídicos. Así, el Código Civil Español, como seguidor de la tendencia iniciada por el Código Francés, el término negocio lo sustituye por la palabra acto, siendo uno de los países más

\footnotetext{
${ }^{76}$ Mauro CAPPELLETTI, dirige en Florencia el Instituto Universitario Europeo dependiente de la CE del cual se ha llegado a decir que es "la Universidad de Bolonia del siglo XX".

${ }^{77}$ Los intentos del nuevo Código Europeo de Contratos pueden tener un mayor apoyo desde el momento que se ha dado en la propia Gran Bretaña un intento de redacción de una ley de Contratos en un intento codificador del Derecho vigente. FERNÁNDEZ de BUJAN, F., Retorno a Roma en la elaboración del Futuro Código Europeo de Contratos, Bol. Fac. Dcho UNED, no 15, ann. 2000, pp. 114 ss.
} 
reticentes a la categoría de los negocios jurídicos. De hecho Zachariae, sustituyó el termino affaire juridique por el de acte juridique (como mala traducción de negocio jurídico).

En Francia, la compraventa es título transmisor de la propiedad ${ }^{78}$. En cambio, tanto en España como en Alemania es solo un título que requiere de la traditio o entrega para producir la transmisión. La idea de la posesión que se tiene en Francia o en España, no es exactamente igual o equivalente que en Alemania (gwere).

No cabe duda que un derecho basado sobre la existencia de una Comunidad Europea como un todo orgánico y único, sería un paso hacia adelante a favor de un Derecho Único. Sobre esta idea es de destacar los progresos sobre Código de Comercio Uniforme, el Código de Contratos y Obligaciones que en contacto con la práctica nos pusiera sobre el camino de un derecho de juristas y no de burócratas.

Después de unos intentos ${ }^{79}$, como la Conferencia de la Haya de 1964, sobre venta internacional de Bienes inmuebles (ULIS) y sobre formación de contratos de compraventa internacional (ULF) que solo fue ratificados por 7 Estados $^{80}$, o en 1968 con la Comisión para el estudio del Derecho y regulación del Comercio Internacional (UNCITRAL), o la Convención de Viena de 1980.

Mención aparte merecen los trabajos a partir del congreso de Pavía de $1990^{81}$, donde se debatieron las bases para la elaboración del Código Europeo de Contratos con representantes de la entonces Comunidad Económica Europea, que actuaron sobre dos premisas fundamentales: la primera, el Principio de la Autonomía de la Voluntad ${ }^{82}$ como denominador común de todos los ordenamientos nacionales europeos. La segunda, el reconocimiento de la raíz e influencia romanística en los principales sistemas de derecho privado europeo. Para ello se adoptó como base de las negociaciones, siguiendo la iniciativa del profesor Gandolfi, un código ya vigente, tomando como tal el libro IV del Código Civil Italiano, como texto intermedio entre el Francés y el alemán. Con ello, se integraría en él todas las modificaciones que resultaren oportunas.

El Anteproyecto de Código europeo de contratos (Libro I) de la Academia de Pavía representa un esfuerzo por encontrar un medio de integración, mediante la ayuda de la legislación, entre los distintos Derechos

\footnotetext{
${ }^{78}$ J. L. DE LOS MOZOS, «La transmisión de la propiedad en el anteproyecto de Código europeo de contratos de la Academia de Pavía», en Noticias de la Unión Europea, núm. 209 (2002), págs. 107 y ss.

${ }^{79}$ Es de destacar la iniciativa del Instituto Internacional para la unificación del Derecho Privado (UNIDROIT), que trató de armonizar el derecho de contratos, publicando en Roma los “Principios sobre contratos internacionales" 1994.

${ }^{80}$ FERNÁNDEZ BUJAN, F., Retorno a Roma en la elaboración del Futuro Código Europeo de Contratos, Bol. Fac. Dcho UNED, no 15, ann. 2000, pp. 109 a 128.

${ }^{81}$ La idea del Proyecto de Pavía se debe -como se ha indicado-, al Prof. Gandolfi quien convocó en 1990, en dicha ciudad, un Congreso de civilistas europeos con la idea fundamental de responder a la pregunta de si la unidad de mercado, recogida reiteradamente en los Tratados del Mercado Común y de la UE, no implicaba necesariamente la unidad de las reglas contractuales aplicables a las transacciones intracomunitarias. GARCIA CANTERO, La traducción española a la parte General del Código Europeo de Contratos, LALEY, no 5629, 2002.

${ }^{82}$ J. L. DE LOS MOZOS, «La regulación del contrato y el problema de la causa», en Revista jurídica del Notariado, 2002, pp. 203 y ss.
} 
europeos, concurriendo con otros intentos que se hallan animados por la misma finalidad, según José Luis De los Mozos $^{83}$.

Del Código Europeo de contratos ya me ocupé en otras ocasiones ${ }^{84}$ y en estas mismas páginas, por ello antes de ocuparme finalmente de las novedades en materia de derecho europeo, la mención a una última quaestio: la formación del futuro jurista Europeo.

En este punto, es muy conveniente no perder de vista la recomendación del Consejo Europeo que desde 1970 ha venido fijando unas pautas comunes a la enseñanza y a la formación jurídicas de los estudiantes europeos, y la adaptación de nuestra Universidad al llamado y a veces denostado Espacio Europeo de Enseñanza Superior, con la finalidad de la búsqueda de la armonización de los diferentes sistemas universitarios europeos.

Entre otras pautas, es la búsqueda de un derecho de juristas bajo la perspectiva de un Derecho Europeo, como lo fue el Derecho Romano, lo que se recomienda. Es la vieja idea del pragmatismo romano nacido bajo el auspicio de ser un derecho que tuviese una solución para todo tipo de problemas.

En el derecho romano clásico, ante la aparición de un caso que no estuviera previsto en los mores o en la lex, el magistrado competente elaboraba su Edictum o el jurisconsulto emitía su responsa aconsejando siempre la solución jurídica más adecuada. Y cuando fue preciso celebrar contratos con extranjeros con vistas a la expansión del mercado internacional, los propios juristas romanos crearon el Ius Gentium ${ }^{85}$.

En todo caso, y como decía KOSCHAKER ${ }^{86}$, "La recepción de un sistema jurídico no es un problema de calidad sino de poder. La convicción de que la superior autoridad espiritual y cultural del Derecho que va a ser adoptado está entroncada con el poder político o con la cultura que representa como algo vivo. La Recepción es ante todo un problema de vigencia práctica, no solo de existencia histórica".

\section{LAS ÚLTIMAS NOVEDADES EN MATERIA DE SUCESIONES EN EUROPA: EL CERTIFICADO SUCESORIO EUROPEO}

Pero sobre todo, ha sido en el ámbito del Derecho internacional privado donde más transformaciones se han producido a nivel europeo y estatal ${ }^{87}$. La entrada en vigor del Reglamento de la Unión Europea (UE) núm.

\footnotetext{
${ }^{83}$ DE LOS MOZOS, El anteproyecto de Código Europeo de Contratos de la Academia de Pavía, Diario La ley, nº 5629. 2002.

${ }^{84}$ ROBLES VELASCO, L.M., EL FUTURO CODIGO EUROPEO DE CONTRATOS, ¿UNA NUEVA RECEPCION?, RIDROM (Revista Internacional de Derecho Romano). Octubre 2010. Disponible en: www.ridrom.uclm.es, $\mathrm{n}^{\circ}$ de Octubre 2010.

${ }^{85}$ TABOSA PINTO, "A recepçao do Direito Romano e seus aspectos sociológicos", ponenc. I Congr. Iberoamericano de Derecho Romano, Granada 1995.

${ }^{86}$ KOSCHAKER, Europa y el Derecho Romano, Madrid 1955, p. 114-115 Y212-213.

${ }^{87}$ Por otra parte, en el marco estatal español son de destacar, las modificaciones realizadas por la Ley 15/2015 de 2 de julio, de la Jurisdicción Voluntaria, que reforma determinadas disposiciones del Código Civil, siguiendo por la Ley Orgánica 7/2015, de 21 de julio, por la que se modifica la Ley Orgánica 6/1985, de 1 de julio, del Poder Judicial, la Ley 29/2015 de 30 de julio, de Cooperación vol.10, nº. 01, Rio de Janeiro, 2017. pp.291-316 
1215/2012, que modifica sensiblemente el régimen de reconocimiento y ejecución de resoluciones en el ámbito comunitario $^{88}$, y la del Reglamento comunitario núm. 650/2012, relativo a la competencia, la ley aplicable, el reconocimiento y la ejecución de las resoluciones judiciales, a la aceptación y la ejecución de los documentos públicos en materia de sucesiones mortis causa y a la creación de un certificado sucesorio europeo ${ }^{89}$.

Este Reglamento (UE) n 650/2012 del Parlamento Europeo y del Consejo de 4 de julio de 2012 no contempla a decir de Calvo Vida ${ }^{90}$, una regulación sustantiva del Derecho de Sucesiones, sino que trata de posibilitar un régimen de cooperación entre estados miembros de la Unión Europea en materia sucesoria. Va más allá de resolver los conflictos de leyes entre naciones al salvar los obstáculos que plantean el reconocimiento de las resoluciones judiciales y la ejecución de documentos públicos. En realidad, el certificado sucesorio europeo posibilita la acreditación de la condición de heredero, legatario, administrador o legitimado testamentario, siempre que el causante haya fallecido después del 17 de agosto de 2015 y siempre que se trate de sucesiones de ciudadanos miembros de Estados de la Unión Europea, -salvo Reino Unido, Irlanda y Dinamarca-, ya que éstos Estados serán considerados para estos efectos como terceros países o no miembros de la Unión.

Ello nos aclara que solo se aplicará este Reglamento a las sucesiones que versen sobre un conflicto sobre competencias internacionales, pero no a las sometidas exclusivamente al derecho interno de un país. Sería el caso, por ejemplo, de la sucesión de un ciudadano francés, con residencia habitual en España, que fallece dejando bienes de la herencia en España, Francia e Italia, en cuyo caso, el sometimiento de la sucesión a las normas del Reglamento no ofrece duda alguna, dado su carácter internacional o transfronterizo ${ }^{11}$. Pero no lo sería si se tratara de la sucesión de un ciudadano miembro de un Estado de la Unión cuyo patrimonio estuviera radicado exclusivamente en su país. Y desde luego no, de un ciudadano no comunitario, aunque su última residencia fuere en país comunitario.

El punto de conexión es el establecimiento de la residencia habitual para la determinación de la ley de la Sucesión. Esta planificación de la sucesión con arreglo a la ley de la residencia habitual va a derivar su régimen

Jurídica Internacional en materia civil, así corno las importantes modificaciones que introduce la Ley 26/2015, de 28 de julio de modificación del sistema de protección a la infancia y a la adolescencia.

${ }^{88}$ ANDREA BONOMI Y PATRICK WAUTELET, El derecho europeo de sucesiones: comentario al Reglamento (UE) núm. 650/2012, de 4 de julio de 2012 (traducida y adaptada al derecho español por Santiago Álvarez González), Ed. Thomson Reuters Aranzadi, Cizur Menor (Navarra), 2015, 781pp. Vid BONOMI, A.,- WAUTELET, P., El Derecho Europeo de Sucesiones. Comentarios al Reglamento (UE) no 650/2012 de 4 de julio de 2012, (versión traducida y adaptada al derecho español por Santiago Álvarez González), Ed. Thomson Reuters-Aranzadi, Cizur Menor (Navarra) 2015,781 pp. Sobre el Certificado Sucesorio Europeo, vid. Art. 62 a 73, pp. 599-706.

${ }^{89}$ Artículo 62. Creación de un certificado sucesorio europeo.

"El presente Reglamento crea el certificado sucesorio europeo (en lo sucesivo denominado «certificado») que se expedirá para ser utilizado en otro Estado miembro y que producirálos efectos enumerados en elartículo 69.

La utilización del certificado no seráobligatoria..."

${ }^{90}$ CALVO VIDAL, I.A., Sucesiones internacionales vs. Sucesiones nacionales, Rev. El notario del Siglo XXI (Col. Not. De Madrid), no 61, Mayo-Junio 2015, p.16-18.

${ }^{91}$ CALVO VIDAL, I.A., Sucesiones internacionales vs. Sucesiones nacionales, ... Op. Cit., p. 18. 
jurídico hacia una ley sucesoria sobrevenida y por tanto sometida a las incidencias que ésta ocasione. Esto puede dar lugar a situaciones paradójicas, si el nacional fuera ciudadano miembro de un Estado y al sobrevenir el fallecimiento hubiera fijado su residencia habitual dentro de otra nación donde rigiera un sistema de pluralismo de régimen jurídico dependiendo de la vecindad civil.

Por ejemplo, un ciudadano francés con parte de su patrimonio en Francia, pero que al final de sus días hubiera fijado su residencia en territorio español foral, como como por ejemplo, Navarra donde no rige el derecho civil común al menos de prima facie. Si en el momento de su fallecimiento hubiera obtenido la vecindad civil Navarra, donde por tanto rige la legislación Foral Navarra y donde ha dispuesto el destino de sus bienes. Curiosamente no se aplicaría la legislación civil común del Código Civil español, sino la legislación Navarra ${ }^{92}$ donde precisamente en su Ley $1^{\text {a }}$ declara al Derecho Romano como derecho supletorio.

Las razones, aparte de antecedentes más o menos históricos ${ }^{93}$, se pueden encontrar en la Ley 1/1973, de 1 de marzo, por la que se aprueba la Compilación del Derecho Civil Foral de Navarra.

Dispone la Ley 1 Navarra que ... "Como expresión del sentido histórico y de la continuidad del derecho privado foral de Navarra, conservan rango preferente para la interpretación e integración de las leyes de la compilación...y el Derecho romano para las instituciones o preceptos que la costumbre o la presente compilación hayan recibido del mismo". Esta ley 1 del "Fuero Nuevo de Navarra" procede de las leyes $1^{a}$ y $7^{\text {a }}$ de la Recopilación privada. Concretamente en la ley 7 a al tratar del derecho supletorio se decía que: "El derecho Supletorio queda integrado por el orden siguiente: 1. La tradición jurídica Navarra contenida en las Leyes de Cortes posteriores a la Novísima Recopilación, la misma Novísima Recopilación, el Amejoramiento del Fuero, el Fuero General y el Derecho Romano. 2. El Derecho Romano, para las instituciones o preceptos que la costumbre o la Recopilación hayan recibido del mismo..." y al declarar la Ley 6: "El Código Civil y las leyes generales de España serán derecho supletorio de esta compilación y de la tradición jurídica navarra expresada en la Ley 1...". Con ello, se llegaría a la conclusión que tanto el Código Civil como las leyes generales españolas serían a su vez supletorios del Derecho Romano ${ }^{94}$.

Por ello cuando todavía se escucha la cansina cuestión de ipara que sirve el Derecho Romano?... simplemente se podría decir que para esto: para aplicar y conocer el Derecho Europeo.

\footnotetext{
${ }^{92}$ Sobre este tema ya me ocupe anteriormente, y se puede consultar, ROBLES VELASCO, L.M., "VIGENCIA DEL SISTEMA SUCESORIO ROMANOENLASCOMPILACIONES FORALES". Editorial: Servicio de publicacións, UNIVERSIDADE DE VIGO, ISBN/ISSN: 84-8158-125-9. Páginas (desde/hasta) 187 -199.

${ }^{93}$ IRURITA KUSARRETA, El Municipio de Pamplona en la Edad Media, Pamplona 1959, p. 267, doc. 85 de Abril de 1355, el rey Carlos II declara que "...como quiere que por nuestro Consejo en el qual eran muchos sauios en drecho et foristas nos trouassemos que de drecho et de fuero..". Con lo cual la penetración del Derecho Romano tuvo en los romanistas del Consejo Real y de la Cort maior sus principales valedores. Como apunta LACARRA, "El Derecho romano no entra tanto por los códigos como por la jurisprudencia de los encargados de aplicarlo en la Cort, y por el uso que hacen de él los abogados y notarios, debido al agotamiento de la legislación indígena". LACARRA, "Sobre la recepción del Derecho Romano en Navarra", AHDE 11 (1934), pp. 457-467.
} 


\title{
BRIEF NOTES ON BASIC ESSENTIALS OF EUROPEAN LAW AND ROMAN LAW
}

\begin{abstract}
Taking into account the possibility of a new subject entitled "Fundamentals of European Law", it is not superfluous to recall the decisive role played by Roman Law in the formation of European Law, its influence in countries like England, Germany, France, Spain and many others, including exotic systems such as Japanese or Indian. In the same way, out of being considered as a mere historic law, on the contrary, it is still in force in present Europe, as most recent developments reaffirm just as the European Obligation Code or Succession Law.
\end{abstract}

Keywords: Fundamentals of European Law; Roman Law; English Law; French Law; Privileged Law; European Union Law; Succession Law; European Certificate of Succession.

\section{BIBLIOGRAFÍA}

A.D. Mc NAIR, Roman Law and Common Law, 2a ed. Cambridge 1952.

AMACHO EVANGELISTA, F., Historia del Derecho Romano y su recepción en Europa, Granada 1994.

A. TORRENT, Intervención en el Seminario de Derecho Romano del 15/06/2016. Universidad Católica de San Antonio, Murcia.

BETANCOURT F., En defensa del Derecho Romano, CIDHPPN,9-10, enero 1988, Barcelona.

CANNATA, Historia de la ciencia jurídica Europea, op. Cit.

CLARAMUNT, Universidad medieval y transmisión de saberes, Valladolid 1997.

CREMADES LIÑAN, La Europa que surge de la paz de Westfalia, op. Cit.

DUPLÁ MARIN, La enseñanza del Derecho Romano, en El Derecho Romano En La Universidad Del Siglo Xxi, op. Cit.

FERNÁNDEZ DE BUJAN F., La Reforma de los Estudios de Derecho, Madrid 1992.

FERNANDEZ-GALIANO y DE CASTRO CID, Lecciones de Teoría del Derecho y Derecho Natural, Madrid 1995.

FONT RIUS, Historia del Derecho Español, Barcelona 1969.

FUENTESECA, P., Historia del Derecho Romano, Madrid 1987.

\footnotetext{
${ }^{94}$ Conclusión ésta en la que coincido con autorizadas voces, como SALINAS QUIJADA, o NAGORE YARNOZ. NAGORE YARNOZ, "Il vigore del Diritto romano in Navarra", Bol. inf. dell'Ist. giur. spagn. di Roma, XI, 40-43 (1963), pp. 18-23. 
GARCÍA GARRIDO, MJ., Derecho Privado Romano, Casos, Acciones e Instituciones, Madrid 2003.

GARCIA GARRIDO, y EUGENIO DIAZ, Estudios De Derecho y formación de juristas, Madrid 1988

GINER DE LOS RIOS, Sobre reformas en nuestras Universidades, Escritos sobre la Universidad, Madrid 1990. H. POTTER, Historical introduction to English Law, London 1958.

J. ESSER: Principio y Norma en la elaboración jurisprudencial del Derecho, trad. española 2º ed., Barcelona 1978. KOSCHAKER, Europa y el Derecho romano, (trad. SANTA CRUZ TEIJERO) Madrid, 1955.

LOPEZ ROSA, Estudios de Derecho y Formación de juristas. Un apunte a propósito de la reforma de los planes de estudio, CIDHPPN, 15-16, febrero 1993, Barcelona.

LOZANO CORBI, Roma y su gran aportación al mundo: el Derecho Romano, Zaragoza 1993.

MICHAVILA Y CALVO, La Universidad española hacia Europa, Madrid 2000.

PANERO GUTIERREZ, R, y otros "El Derecho Romano En La Universidad Del Siglo XXI”, Cáp. 2ª, El Derecho Romano y su recepción en Europa, op. Cit.

ROBLES VELASCO, L.M., El Futuro Codigo Europeo De Contratos, ¿Una Nueva Recepcion?, RIDROM (Revista Internacional de Derecho Romano). Octubre 2010. Disponible en: www.ridrom.uclm.es, no de Octubre $-2010$.

Trabalho enviado em 27 de setembro de 2016.

Aceito em 04 de janeiro de 2017. 